OAK RIDGE
NATIONAL LABORATORY

MANAGED BY UT-BATTELLE

FOR THE DEPARTMENT OF ENERGY

\title{
Revisiting the Recommended Geometry for the Diametrally Compressed Ceramic C-Ring Specimen
}

\author{
Osama M. Jadaan \\ College of Engineering, Mathematics, and Science \\ University of Wisconsin-Platteville \\ Platteville, WI 53818 \\ jadaan@uwplatt.edu \\ Andrew A. Wereszczak \\ Ceramic Science and Technology Group \\ Materials Science and Technology Division \\ Oak Ridge National Laboratory \\ Oak Ridge, TN 37831-6068 \\ wereszczakaa@ornl.gov
}

Publication Date: April 2009

Prepared by the

OAK RIDGE NATIONAL LABORATORY

Oak Ridge, Tennessee 37831

managed by

UT-BATTELLE, LLC

for the

U.S. DEPARTMENT OF ENERGY

Under contract DE-AC05-00OR22725 


\section{DOCUMENT AVAILABILITY}

Reports produced after January 1, 1996, are generally available free via the U.S. Department of Energy (DOE) Information Bridge:

Web site: http://www.osti.gov/bridge

Reports produced before January 1, 1996, may be purchased by members of the public from the following source:

National Technical Information Service

5285 Port Royal Road

Springfield, VA 22161

Telephone: 703-605-6000 (1-800-553-6847)

TDD: $703-487-4639$

Fax: 703-605-6900

E-mail: info@ntis.fedworld.gov

Web site: http://www.ntis.gov/support/ordernowabout.htm

Reports are available to DOE employees, DOE contractors, Energy Technology Data Exchange (ETDE) representatives, and International Nuclear Information System (INIS) representatives from the following source:

Office of Scientific and Technical Information

P.O. Box 62

Oak Ridge, TN 37831

Telephone: 865-576-8401

Fax: 865-576-5728

E-mail: reports@osti.gov

Web site: http://www.osti.gov/contact.html

This report was prepared as an account of work sponsored by an agency of the United States Government. Neither the United States government nor any agency thereof, nor any of their employees, makes any warranty, express or implied, or assumes any legal liability or responsibility for the accuracy, completeness, or usefulness of any information, apparatus, product, or process disclosed, or represents that its use would not infringe privately owned rights. Reference herein to any specific commercial product, process, or service by trade name, trademark, manufacturer, or otherwise, does not necessarily constitute or imply its endorsement, recommendation, or favoring by the United States Government or any agency thereof. The views and opinions of authors expressed herein do not necessarily state or reflect those of the United States Government or any agency thereof. 
TABLE OF CONTENTS

Page

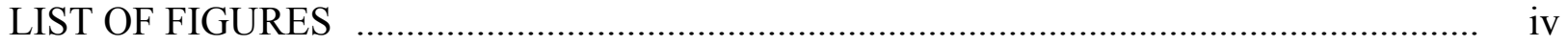

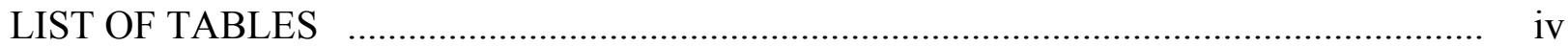

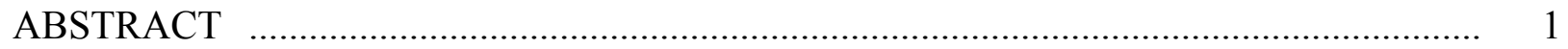

1. INTRODUCTION ................................................................................. 2

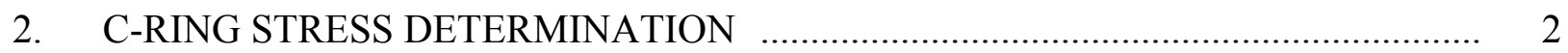

3. EFFECT OF GEOMETRY ……………………………………………..... 8

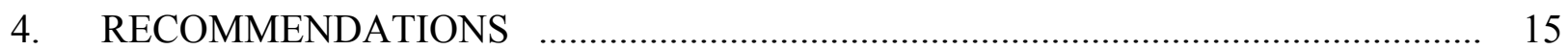

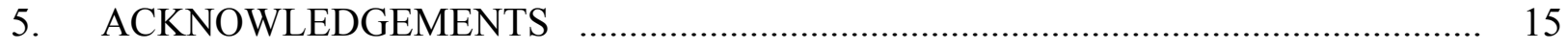

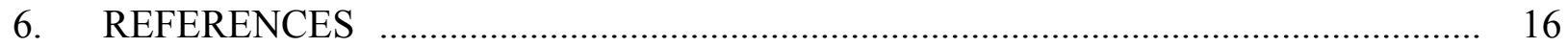




\section{LIST OF FIGURES}

Figure

Page

1. Schematic of the C-ring specimen.

2. Comparison between the elasticity and mechanics solutions for the C-ring specimen as function of inner to outer radii ratio.

3. Maximum circumferential tensile stress as function of specimen geometry (adopted from Ref. 2).

4. One-quarter quarter symmetric model for four of the $20 \mathrm{C}$-ring geometries considered in this study. The width in the figures is half of the actual C-ring width (symmetry).

5. Mesh distribution of ANSYS Solid95 type elements.

6. Hoop stress distribution in the C-ring. Note that the maximum hoop stress occurs at the edge of the specimen.

7. \% difference between mechanics solution and FEA for maximum hoop stress value as function of $r_{i} / r_{o}$ and $b / t$.

8. Stress uniaxiality ratio $\left(\sigma_{\theta} / \sigma_{z}\right)$ as function of $b / t$ and $r_{i} / r_{o}$.

9. Absolute value of the stress uniaxiality ratio $\left(\sigma_{\theta} / \sigma_{z}\right)$ as function of $b / t$ and $r_{i} / r_{o}$. The scale for the uniaxiality ratio is zoomed in to highlight the demarcation below and above a value of 10 .

10. Ratio of edge hoop stress to center hoop stress at 3-o'clock position of outer surface as function of $b / t$ and $r_{i} / r_{0}$.

\section{LIST OF TABLES}

Table

I. Simulation matrix and FEA results for various C-ring geometries. 


\begin{abstract}
A study conducted several years ago found that a stated allowable width/thickness $(\mathrm{b} / \mathrm{t})$ ratio in ASTM C1323 (Standard Test Method for Ultimate Strength of Advanced Ceramics with Diametrally Compressed C-Ring Specimens at Ambient Temperature) could ultimately cause the prediction of a non-conservative probability of survival when the measured C-ring strength was scaled to a different size. Because of that problem, this study sought to reevaluate the stress state and geometry of the C-ring specimen and suggest changes to ASTM C1323 that would resolve that issue. Elasticity, mechanics of materials, and finite element solutions were revisited with the C-ring geometry. To avoid the introduction of more than $2 \%$ error, it was determined that the $\mathrm{C}$-ring width/thickness $(\mathrm{b} / \mathrm{t})$ ratio should range between 1-3 and that its inner radius/outer radius $\left(\mathrm{r}_{\mathrm{i}} / \mathrm{r}_{\mathrm{o}}\right)$ ratio should range between $0.50-0.95$. ASTM C1323 presently allows for $\mathrm{b} / \mathrm{t}$ to be as large as 4 so that ratio should be reduced to 3 .
\end{abstract}




\section{INTRODUCTION}

The ASTM Standard Test Method for Ultimate Strength of Advanced Ceramics with Diametrally Compressed C-Ring Specimens at Ambient Temperature [1] has been available for over 10 years. However, a study conducted several years ago [2] found that a stated allowable width/thickness $(\mathrm{b} / \mathrm{t})$ ratio in that standard could ultimately lead to non-conservative probability

of survival when the measured C-ring strength was scaled to a different size. That is problematic and deserves remedy.

The objective of this study was to reevaluate the stress state and geometry of the C-ring specimen, and suggest changes to ASTM C1323 that would resolve what was observed in Ref. 2. The primary issues investigated were:

1) which C-ring stress formula or numerical technique to use in the standard? and

2) what geometric boundaries (inner to outer radii ratio, ri/ro, and width to thickness ratio, $\mathrm{b} / \mathrm{t}$ ) would desirably maintain hoop stress uniaxiality, and uniformity along specimen width?

\section{C-Ring Stress Determination}

In general there are three approaches to compute the stress state in a C-ring specimen (geometry shown in Fig. 1). These are:

- "Elasticity" solution as described Timoshenko and Goodier [3],

- "Mechanics of materials" solution using curved beam theory [4-5], and

- Finite element analysis (FEA) method.

What differences exist between the elasticity and mechanics of materials solutions? Both have closed form solutions for the C-ring geometry. An effective way to examine any difference is to explore how they deviate as a function of $r_{i} / r_{0}$. It is important to note that in reality two geometric parameters, $\mathrm{r}_{\mathrm{i}} / \mathrm{r}_{\mathrm{o}}$ and $\mathrm{b} / \mathrm{t}$, affect the stress state in a C-ring. However, the elasticity and mechanics solutions assume the specimen to be narrow; namely, under plane stress condition. In other words, these two approaches predict the stress distribution to be independent of the width, b. Of course the magnitude of the stress would scale linearly with $b$, but the distribution will remain unchanged. A plane stress condition also means that the stress along the axial direction (width) of the specimen, $\sigma_{z}$, is assumed to be zero. 


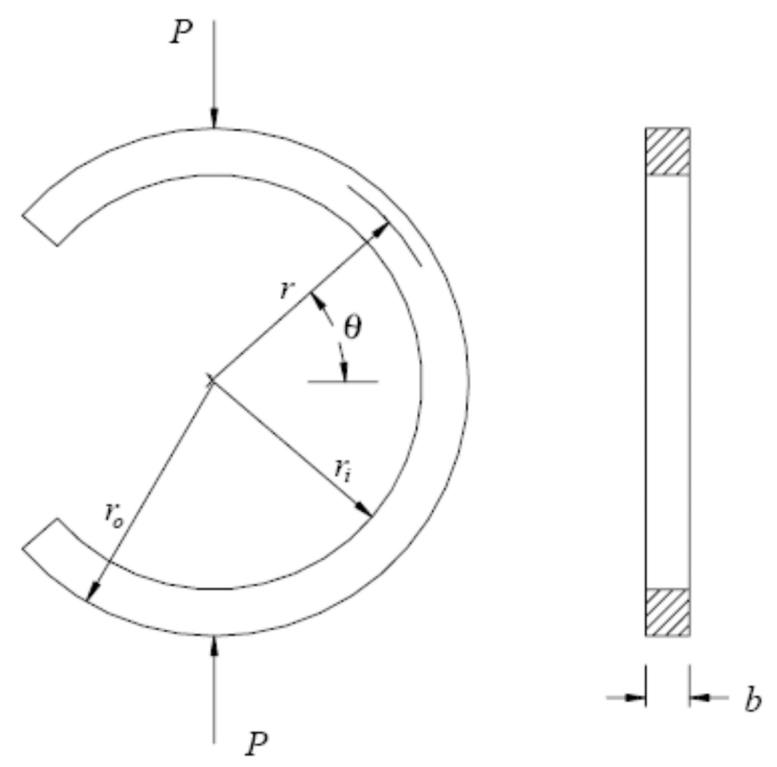

Figure 1. Schematic of the $\mathrm{C}$-ring specimen. $\mathrm{P}$ is the compressive force, $\mathrm{r}_{\mathrm{o}}$ is the outer radius and $r_{i}$ is the inner radius, and $b$ is the width. Thickness, $t$, is $r_{0}-r_{i}$. 
The elasticity solution describes the stress state in a diametrally compressed C-ring as follows [3]:

$$
\begin{aligned}
& \sigma_{r}=\left(2 A r-\frac{2 B}{r^{3}}+\frac{D}{r}\right) \sin \beta \\
& \sigma_{\theta}=\left(6 A r+\frac{2 B}{r^{3}}+\frac{D}{r}\right) \sin \beta \quad \sigma_{z}=0 \\
& \tau_{r \theta}=-\left(2 A r-\frac{2 B}{r^{3}}+\frac{D}{r}\right) \cos \beta \\
& A=\frac{P}{2 N} \quad B=\frac{-P r_{i}^{2} r_{o}^{2}}{2 N} \quad D=\frac{-P}{N}\left(r_{i}^{2}+r_{o}^{2}\right) \\
& N=r_{i}^{2}-r_{o}^{2}+\left(r_{i}^{2}+r_{o}^{2}\right) \ln \left(\frac{r_{0}}{r_{i}}\right) \\
& \sigma_{\theta, \max }=\frac{P}{N}\left[3 r_{o}-\frac{r_{i}^{2}}{r_{o}}-\frac{r_{i}^{2}+r_{o}^{2}}{r_{o}}\right] \\
& \beta=90-\theta
\end{aligned}
$$

where $\mathrm{P}$ is the load per unit width. 
The mechanics of materials solution describes the stress state in a diametrally compressed C-ring as follows [4-5]:

$$
\begin{array}{ll}
\sigma_{r}=\sigma_{z}=0 & \\
P=\text { Load } & \\
\sigma_{\theta}=\frac{P R}{b t r}\left[\frac{r-r_{a}}{r_{a}-R}\right] \cos \theta & \quad t=r_{o}-r_{i} \\
R=\frac{r_{o}-r_{i}}{\ln \left(\frac{r_{o}}{r_{i}}\right)} & r_{a}=\frac{r_{o}+r_{i}}{2} \\
\sigma_{\theta, \max }=\frac{P R}{b t r_{o}}\left[\frac{r_{o}-r_{a}}{r_{a}-R}\right] &
\end{array}
$$

Summarizing the elasticity and mechanics of materials solutions:

- The elasticity solution assumes a biaxial stress state in the C-ring where both hoop stress and radial stress $\left(\sigma_{\mathrm{r}}\right)$ components may exist in the $\mathrm{C}$-ring, along with shear stress.

- The mechanics of materials solution assumes the radial stress component to be zero.

- Both approaches assume the axial stress along specimen width to vanish $\left(\sigma_{z}=0\right)$. 
The following contrasts the elasticity and mechanics of materials solutions:

1) Both approaches neglect the axial stress along the width of the C-ring specimen (z-direction). This is because the specimen is assumed to have a narrow (small width) rectangular cross section, resulting in a 2-D (biaxial) stress state.

2) Since both the elasticity and mechanics of materials solutions are based on 2-D plane stress analyses, they do not account for the effect of the C-ring width on the stress state as it transitions from plane stress to plane strain condition.

3) The elasticity and mechanics of materials hoop stress solutions throughout the specimen, including the maximum stress location, are within $2 \%$ of each other for C-rings with $\mathrm{r}_{\mathrm{i}} / \mathrm{r}_{\mathrm{o}}>0.53$ (see Fig. 2). The elasticity solution always yields higher circumferential stress than the mechanics of materials solution.

4) As can be seen in Fig. 2, as the $\mathrm{r}_{\mathrm{i}} / \mathrm{r}_{0}$ ratio decreases (increasing thickness), the discrepancy between the elasticity and mechanics of materials solutions increases. For example, the difference between the two maximum stress solutions reaches $5.4 \%$ for $r_{i} / r_{o}=1 / 3$.

5) Hence, it would be constructive if ASTM C1323 [1] delineated an $r_{i} / r_{o}$ ratio threshold above which the mechanics of materials solution should be used and below which the elasticity solution should be used. A $2 \%$ difference was sought as a threshold error in this study. Therefore, in order to use the mechanics of materials solution with confidence that the maximum stress value is within $2 \%$ of the maximum stress of the (more accurate) elasticity solution, then $\mathrm{r}_{\mathrm{i}} / \mathrm{r}_{\mathrm{o}}>0.53$.

6) The advantages for using the mechanics of materials solution include simplicity, alreadyderived effective size formulas, and being more conservative (predicting lower stress at failure) compared to the elasticity solution. In addition, Fig. 3 taken from Duffy et. al. [2] shows the mechanics of materials solution resulting in a closer maximum stress value to the FEA simulation at the center of the specimen's width (compared to that of the elasticity solution).

7) As will be seen later, geometric considerations will lead to recommending that $r_{i} / r_{o}$ be greater than 0.50 . Thus, as long as $r_{i} / r_{0}>0.50$, the mechanics of materials solution is probably more appropriate for use in ASTM C1323.

8) For cases where $r_{i} / r_{0}<0.50$, it is recommended that FEA be utilized because (as will be discussed later) stress uniaxiality is no longer maintained in the specimen. 


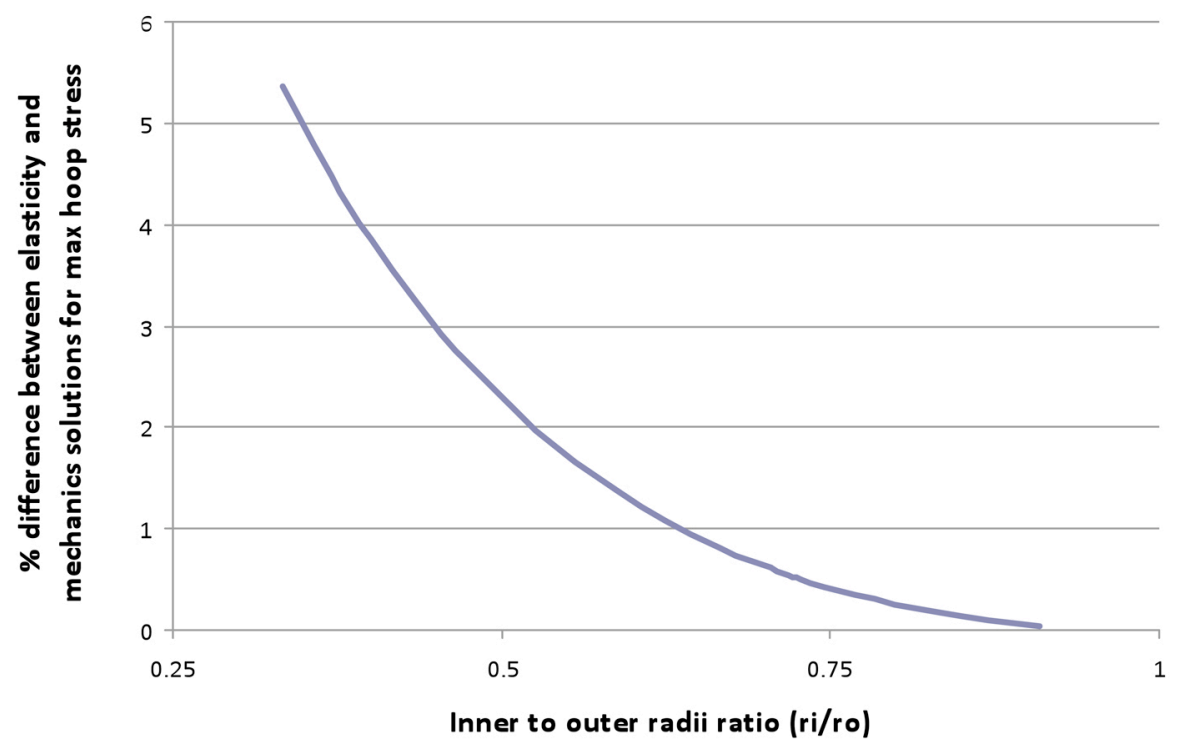

Figure 2. Comparison between the elasticity and mechanics solutions for the C-ring specimen as function of inner to outer radii ratio $\left(\mathrm{r}_{\mathrm{i}} / \mathrm{r}_{\mathrm{o}}\right)$.

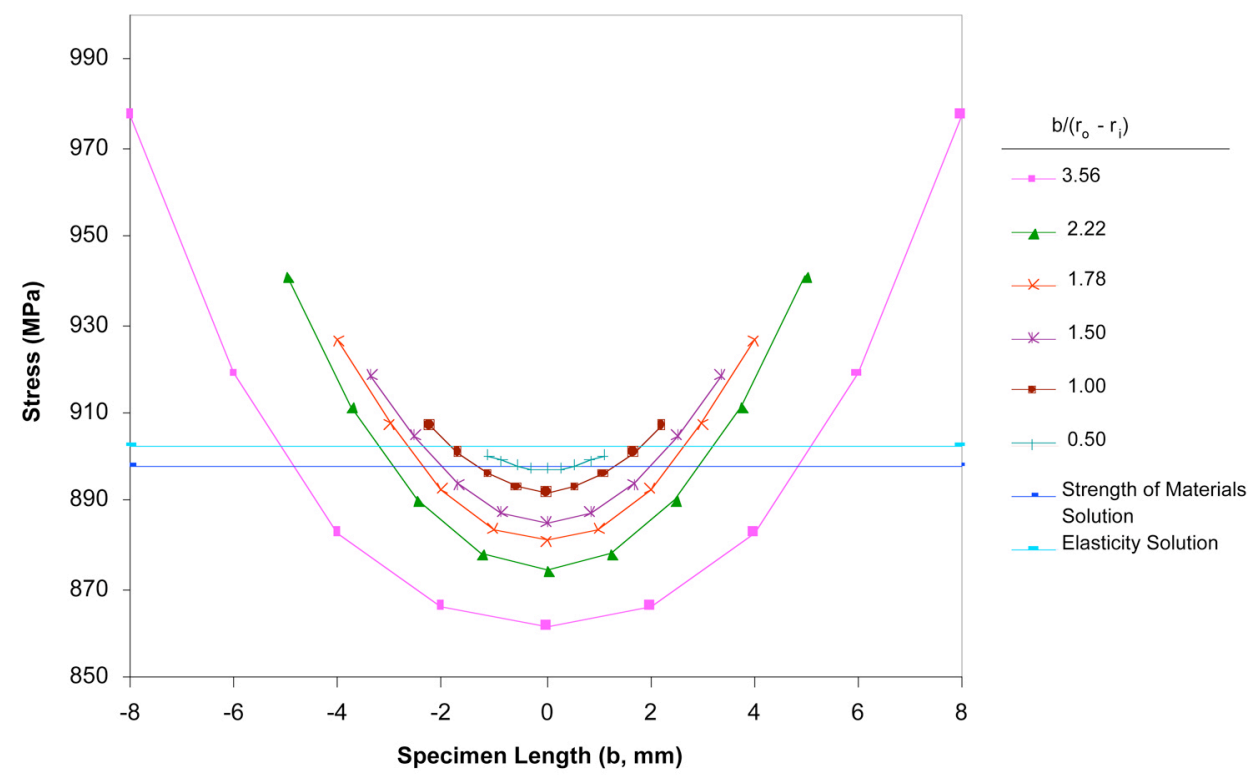

Figure 3. Maximum circumferential tensile stress as function of specimen geometry (from Ref. 2). 


\section{EFFECT OF GEOMETRY}

Unlike the closed form solutions, FEA has the advantage of modeling the 3-D stress state in the C-ring taking into account the effects of both geometric parameters, $r_{i} / r_{o}$ and $b / t$. As stated earlier, the closed form solutions ignore the influence of specimen width (b) on the stress state.

In light of the discussion in Section 2, the mechanics of materials solution will be compared to the FEA numerical solution.

Embree and Segall [6] used FEA to study the effect of C-ring geometry on its state of stress uniaxiality. They defined stress uniaxiality to occur when $\sigma_{\theta} / \sigma_{z}>10$ at the center of the outer surface of the C-ring specimen at the 3-o'clock position (Fig 1). Embree and Segall performed FEA simulations using the matrix shown in Table I. The present study replicated the same simulations and expanded on their published results in the revisitation of the C-ring geometry. In all of these simulations, an outer radius of $50.8 \mathrm{~mm}$ and Poisson's ratio of 0.155 were kept constant, while $b$ and $r_{i}$ were varied. Furthermore, all C-ring configurations were loaded to produce the same maximum hoop stress of $100 \mathrm{MPa}$.

Figure 4 displays four of the $20 \mathrm{C}$-ring geometries considered in this study. Figure 5 shows a typical mesh distribution used to simulate the one-quarter symmetric C-ring model using Solid95 elements in ANSYS. Figure 6 displays a typical hoop stress distribution in a C-ring. It is to be noted that the maximum hoop stress occurs at the edge of the specimen - an indication the stress state is deviating from a plane stress condition. 

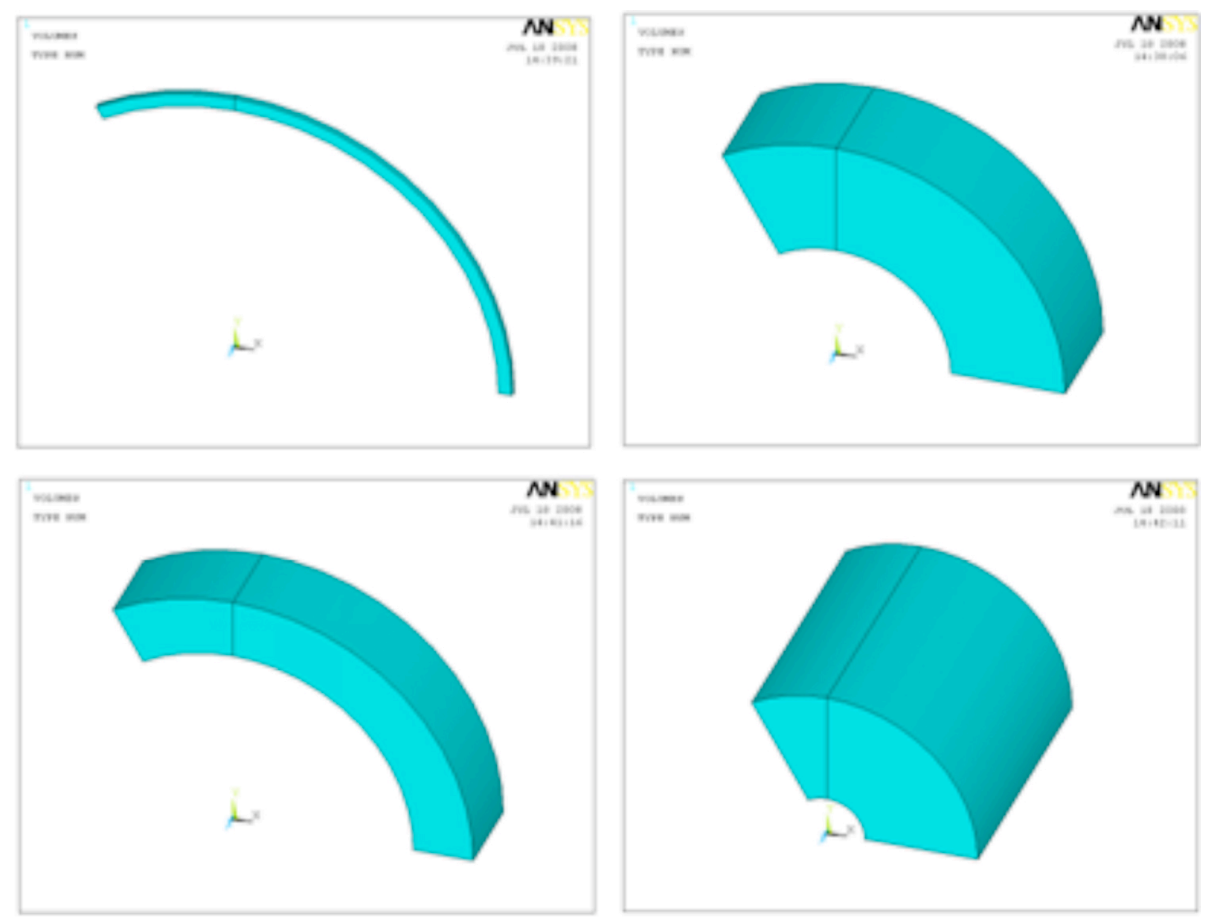

Figure 4. One-quarter symmetric model for four of the $20 \mathrm{C}$-ring geometries considered in this study. The width in the figures is half of the actual C-ring width (symmetry).

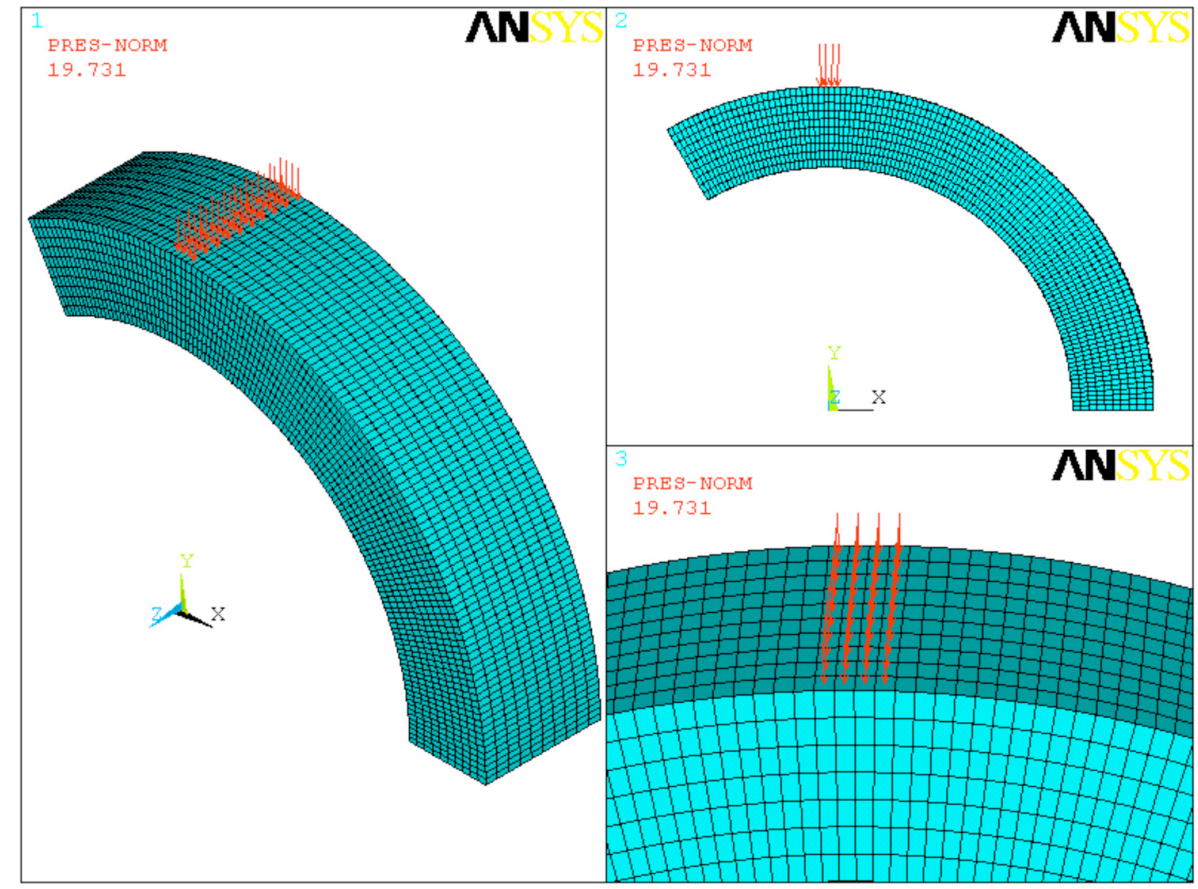

Figure 5. Mesh distribution of ANSYS Solid95 type elements. 


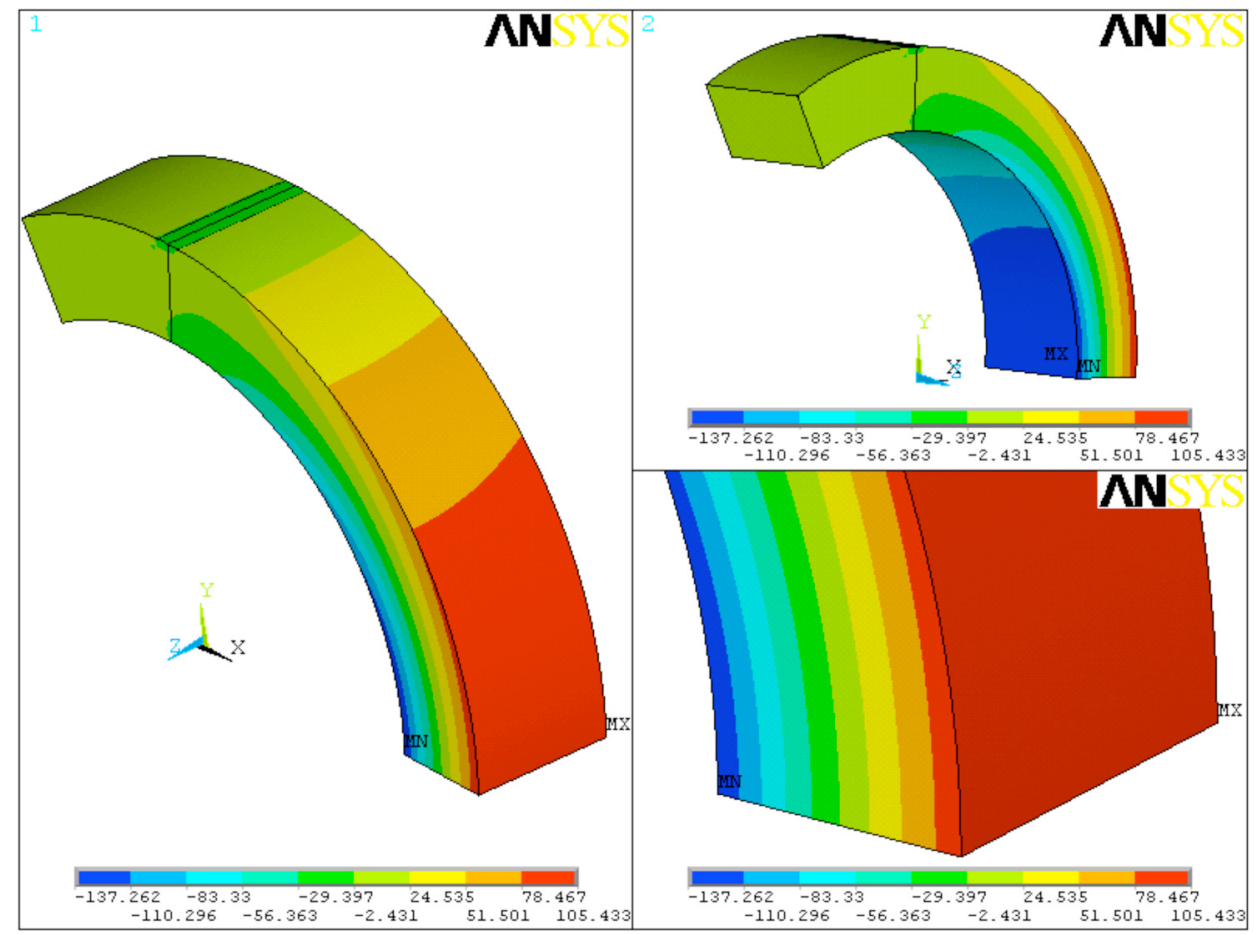

Figure 6. Hoop stress distribution in the C-ring. Note that the maximum hoop stress occurs at the edge of the specimen. 
Table I. Simulation matrix and FEA results for various C-ring geometries.

\begin{tabular}{|c|c|c|c|c|c|c|c|c|c|}
\hline $\mathrm{P}(\mathrm{N})$ & $\mathrm{b}$ & $\mathrm{t}$ & $\mathrm{r}_{\mathrm{i}} / \mathrm{r}_{\mathrm{o}}$ & $\mathrm{b} / \mathrm{t}$ & $\begin{array}{c}\% \\
\text { difference } \\
\text { between } \\
\text { theory and } \\
\text { FEA }\end{array}$ & $\sigma_{\theta} / \sigma_{\mathrm{z}}$ & $\begin{array}{c}\sigma_{\theta_{-} \text {edge }} \\
\sigma_{\theta_{-} \text {center }}\end{array}$ & $\mathrm{Ve} / \mathrm{V}$ & $\mathrm{Ae} / \mathrm{A}$ \\
\hline 60096.15 & 38.1 & 38.1 & 0.25 & 1 & -7.54 & 10754 & 1.035 & 0.0190 & 0.0966 \\
10250.5 & 25.4 & 25.4 & 0.5 & 1 & -1.49 & -283.5 & 1.022 & 0.0163 & 0.0805 \\
888.68 & 12.7 & 12.7 & 0.75 & 1 & -0.06 & -365.2 & 1.010 & 0.0157 & 0.0730 \\
5.66 & 2.54 & 2.54 & 0.95 & 1 & -0.01 & -133345 & 1.002 & 0.0141 & 0.0682 \\
120192.3 & 76.2 & 38.1 & 0.25 & 2 & -7.25 & 13.3 & 1.064 & 0.0151 & 0.0988 \\
20501 & 50.8 & 25.4 & 0.5 & 2 & -0.15 & 26.7 & 1.066 & 0.0125 & 0.0788 \\
1777.35 & 25.4 & 12.7 & 0.75 & 2 & 0.94 & 185.9 & 1.040 & 0.0134 & 0.0787 \\
11.32 & 5.08 & 2.54 & 0.95 & 2 & 0.20 & -10848 & 1.008 & 0.0137 & 0.0840 \\
180288.45 & 114.3 & 38.1 & 0.25 & 3 & -8.45 & 8.4 & 1.056 & 0.0147 & 0.1064 \\
30751.5 & 76.2 & 25.4 & 0.5 & 3 & -0.25 & 10.2 & 1.082 & 0.0109 & 0.0763 \\
2666.03 & 38.1 & 12.7 & 0.75 & 3 & 1.96 & 29.7 & 1.075 & 0.0109 & 0.0718 \\
16.97 & 7.62 & 2.54 & 0.95 & 3 & 0.52 & 12435.0 & 1.018 & 0.0129 & 0.0879 \\
240384.6 & 152.4 & 38.1 & 0.25 & 4 & -9.30 & 7.8 & 1.045 & 0.0152 & 0.1160 \\
41002 & 101.6 & 25.4 & 0.5 & 4 & -1.20 & 7.4 & 1.073 & 0.0107 & 0.0793 \\
3554.70 & 50.8 & 12.7 & 0.75 & 4 & 2.36 & 13.5 & 1.098 & 0.0095 & 0.0666 \\
22.63 & 10.16 & 2.54 & 0.95 & 4 & 0.95 & 300.2 & 1.031 & 0.0120 & 0.0862 \\
300480.75 & 190.5 & 38.1 & 0.25 & 5 & -9.61 & 7.8 & 1.040 & 0.0156 & 0.1232 \\
51252.5 & 127 & 25.4 & 0.5 & 5 & -2.10 & 6.7 & 1.061 & 0.0109 & 0.0840 \\
4443.38 & 63.5 & 12.7 & 0.75 & 5 & 2.00 & 8.9 & 1.100 & 0.0090 & 0.0658 \\
28.29 & 12.7 & 2.54 & 0.95 & 5 & 1.46 & 117.9 & 1.047 & 0.0111 & 0.0816 \\
\hline
\end{tabular}

* The last two columns refer to the effective volume/volume ratio and the effective area to area ratio for Weibull modulus $m=10$.

Continuing the theme of Section 1, Fig. 7 shows how the FEA solution deviates from the mechanics solution as a function of $b / t$ and $r_{i} / r_{0}$. This figure is essentially a topographic map where the colors indicate the \% difference between the FEA and mechanics of materials approaches as function of $r_{i} / r_{o}$ and $b / t$. For example, for a C-ring specimen with $b / t=4$ and $r_{i} / r_{o}=0.75$, the mechanics of materials solution for the maximum hoop stress at the center of outer surface at the 3-o'clock position deviates by $2-4 \%$ (see legend) from that of the FEA simulation.

For an error less than $2 \%$, the C-ring specimens within the purple region of Fig. 7 would satisfy that criterion. As can be seen from this figure, keeping the C-ring $b / t$ between 1-3 and $r_{i} / r_{o}$ between 0.50 and 0.95 would ensure that the mechanics of materials stress formula (Eq. 2) be within $2 \%$ of the FEA solution. As expected, Fig. 7 shows that as a C-ring gets wider and thicker, the FEA and mechanics solutions deviate accordingly. This is because the C-ring approaches plane strain rather than the assumed plane stress condition inherent in the mechanics of materials and elasticity theories. For example, the mechanics solution for maximum hoop stress in a C-ring with $3<\mathrm{b} / \mathrm{t}<5$ and $\mathrm{r}_{\mathrm{i}} / \mathrm{r}_{\mathrm{o}}=0.25$ differ by $8-10 \%$ from that predicted by FEA. 


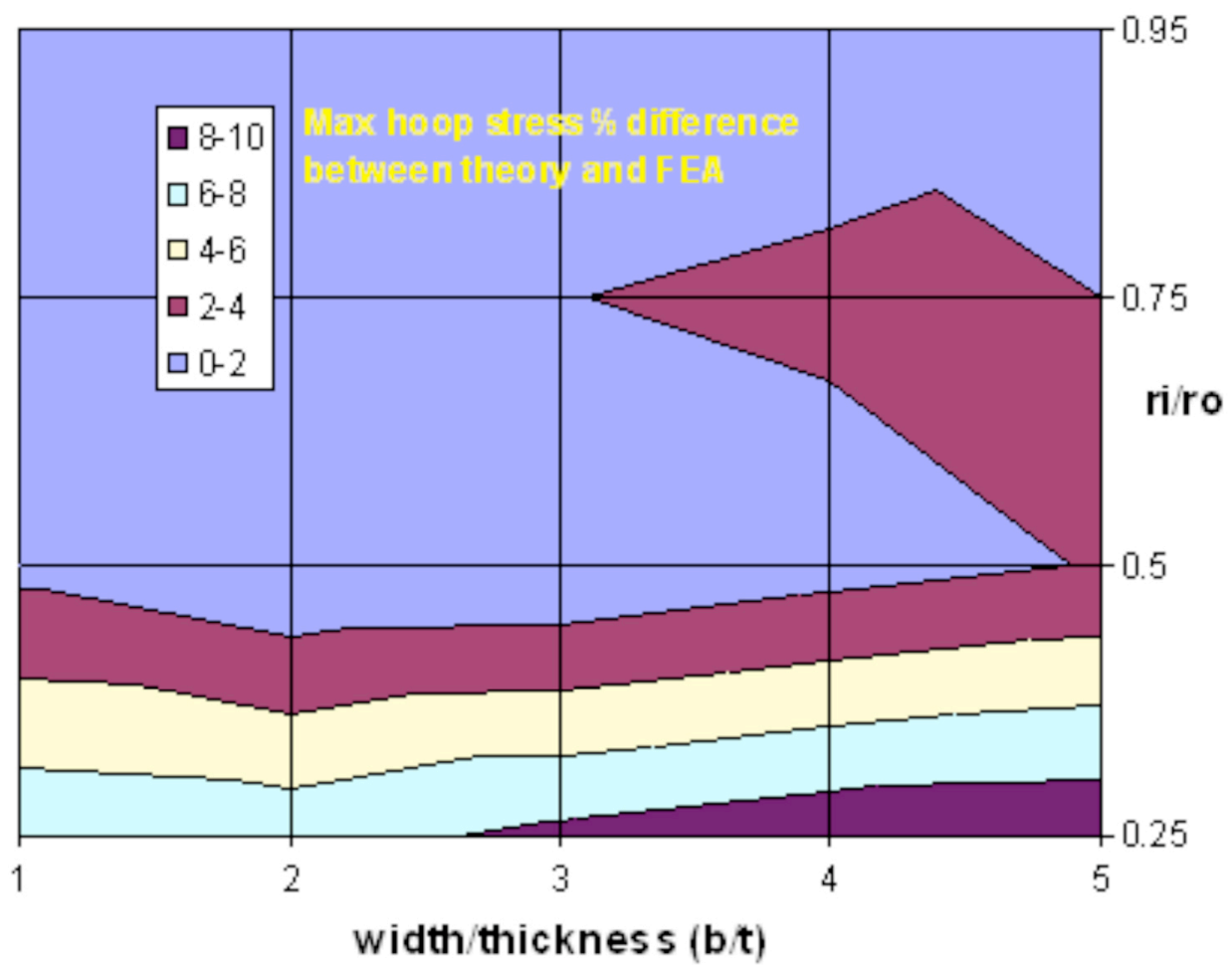

Figure 7. \% difference between mechanics solution and FEA for maximum hoop stress value as function of $r_{i} / r_{o}$ and $b / t$.

The ratio of the hoop stress to axial stress $\left(\sigma_{\theta} / \sigma_{z}\right)$ at the center of the outer surface at the 3-o'clock position is used to assess the uniaxiality of stress state in the C-ring specimen. As $\sigma_{\theta} / \sigma_{z}$ decreases, the C-ring specimen deviates from uniaxiality and plane stress condition and approaches that of multiaxiality and plane strain condition. A goal should be to standardize the ASTM C-ring specimen with a uniaxial stress state.

Embree and Segall [6] stated that if $\sigma_{\theta} / \sigma_{z}>10$ then the specimen can be assumed to be in a uniaxial stress state. The present study will adopt their argument in this report. However, the results computed and included in this report are robust enough to permit changing this value and designing specimen geometries to obey whatever uniaxiality ratio one deems suitable.

Figure 8 displays a topographic map of the uniaxiality ratio as function of $b / t$ and $r_{i} / r_{0}$. The computed uniaxiality ratios are widespread in this figure. In order to see the demarcation below and above the uniaxiality ratio of 10, Fig. 9 zooms in at values between -50 and 50 and clearly shows where this ratio goes below 10 . 
Per Fig. 9, in order to keep the uniaxiality ratio above 10, the following geometries must be maintained:

- $\quad 1<\mathrm{b} / \mathrm{t}<3$ and any $\mathrm{r}_{\mathrm{i}} / \mathrm{r}_{\mathrm{o}}$ above 0.25 ,

- $\quad 3<\mathrm{b} / \mathrm{t}<4$ and $\mathrm{r}_{\mathrm{i}} / \mathrm{r}_{\mathrm{o}}>0.50$, and

- $4<\mathrm{b} / \mathrm{t}<5$ and $\mathrm{r}_{\mathrm{i}} / \mathrm{r}_{\mathrm{o}}>0.75$.

A union of these recommendations, and that made earlier to keep the FEA and mechanics of materials solutions within $2 \%$ of each other, leads to the same conclusion that the C-ring geometry should have its $b / t$ between $1-3$ and $r_{i} / r_{o}$ between $0.50-0.95$. ASTM C1323 presently allows for $\mathrm{b} / \mathrm{t}$ to be as large as 4 ; the present analysis recommends that this be reduced to 3 .

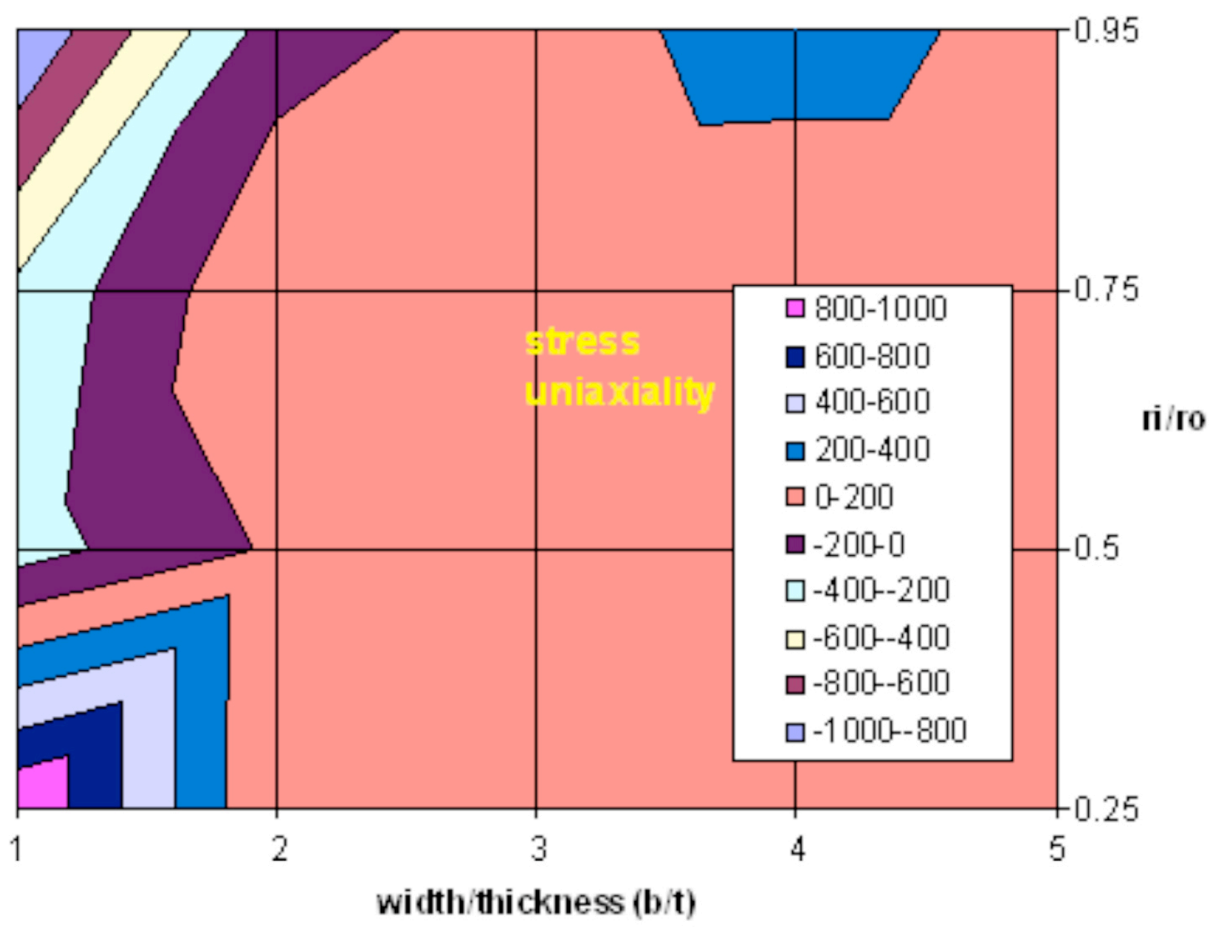

Figure 8. Stress uniaxiality ratio $\left(\sigma_{\theta} / \sigma_{z}\right)$ as function of $b / t$ and ri/ro. 


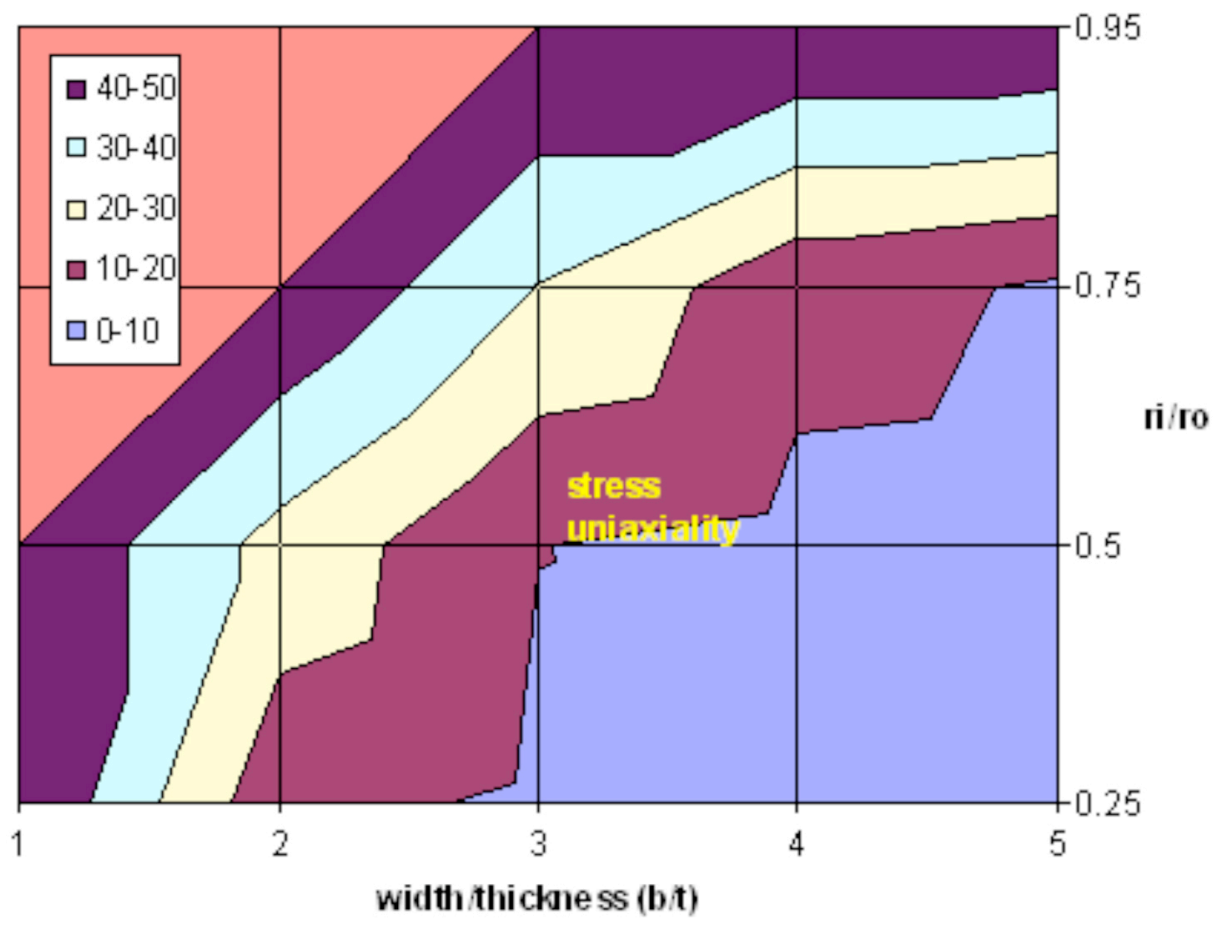

Figure 9. Absolute value of the stress uniaxiality ratio $\left(\sigma_{\theta} / \sigma_{z}\right)$ as function of $b / t$ and $\mathrm{r}_{\mathrm{i}} / \mathrm{r}_{\mathrm{o}}$. The scale for the uniaxiality ratio is zoomed in to highlight the demarcation below and above a value of 10 .

Uniformity of the hoop stress distribution along the width of the C-ring specimen is yet another parameter that can be used to assess the plane stress state in the specimen. In addition, this parameter is important because it can be used to avoid edge failures in C-rings due to significantly higher edge hoop stress. Figure 10 shows a topographic map of the ratio of edge hoop stress to center hoop stress at 3-o'clock poison of outer surface as function of $b / t$ and $r_{i} / r_{o}$. As can be seen from Fig. 10, if the edge stresses are to be kept low (equal to that at the center), then $\mathrm{C}$-rings should tend to be narrow and thin. 


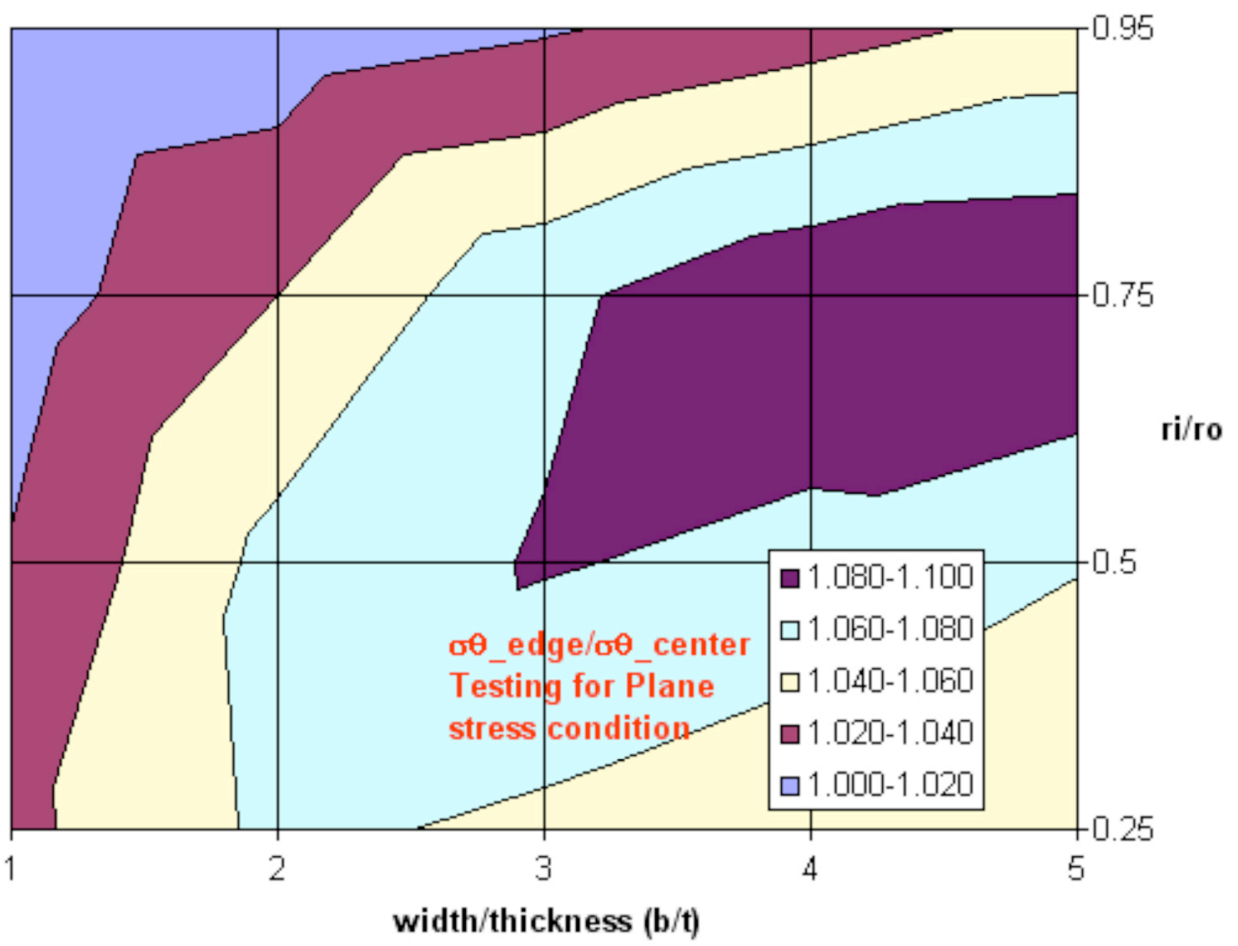

Figure 10. Ratio of edge hoop stress to center hoop stress at 3-o'clock position of outer surface as function of $b / t$ and $r_{i} / r_{o}$.

\section{RECOMMENDATIONS}

Based on the analysis and parameters considered in the work, a C-ring specimen's geometry should be maintained within the following ranges:

$$
1 \leq \mathrm{b} / \mathrm{t} \leq 3 \quad \text { and } \quad 0.50 \leq \mathrm{r}_{\mathrm{i}} / \mathrm{r}_{\mathrm{o}} \leq 0.95
$$

ASTM C1323 presently allows for $\mathrm{b} / \mathrm{t}$ to be as large as 4 ; that should be reduced to 3 . Of course there are stability issues with very thin specimens. These are up to the experimentalists to decide. Lastly, this investigation was performed using Poisson's ratio $=0.155$; the recommended values of $b / t$ and $r_{i} / r_{o}$ may change somewhat for different Poisson's ratios.

\section{ACKNOWLEDGEMENTS}

Research sponsored by the U.S. Department of Energy, Assistant Secretary for Energy Efficiency and Renewable Energy, Office of Vehicle Technologies, as part of the Propulsion Materials Program, under contract DE-AC05-00OR22725 with UT-Battelle, LLC. The authors thank J. -A. Wang and H. Wang for reviewing the manuscript. 


\section{REFERENCES}

[1] "Standard Test Method for Ultimate Strength of Advanced Ceramics with Diametrally Compressed C-Ring Specimens at Ambient Temperatures," ASTM C1323-96, Vol. 15.01, ASTM International, West Conshohocken, PA, 2008.

[2] S. F. Duffy, E. H. Baker, A. A. Wereszczak, and J. J. Swab, "Weibull Analysis Effective Volume and Effective Area for a Ceramic C-Ring Test Specimen," Journal of Testing and Evaluation, 33:233-238 (2005).

[3] S. P. Timoshenko and J. N. Goodier, Theory of Elasticity, McGraw-Hill, 1970.

[4] M. K. Ferber, V. J. Tennery, S. B. Waters, and J. Ogle, "Fracture Strength Characterization of Tubular Ceramic Materials Using a Simple C-ring Geometry," Journal of Materials Science, 21:2628-2632 (1986).

[5] O. M. Jadaan, D. L. Shelleman, J. C. Conway, Jr., J. J. Mecholsky, Jr., and R. E. Tressler, "Prediction of the Strength of Ceramic Tubular Components: I-Analysis," Journal of Testing and Evaluation, 19:181-191 (1991).

[6] T. Embree and A. Segall, "Evaluation of the Uniaxiality of the Stress State in C-Ring Fracture Strength Specimens," Journal of Testing and Evaluation, 32:153-160 (2004). 